URL:http://ojs.unimal.ac.id/index.php/ekonomi_regional

\title{
Pengaruh Dana Desa Dan Alokasi Dana Gampong Terhadap Kemiskinan Di Kecamatan Makmur Kabupaten Bireuen
}

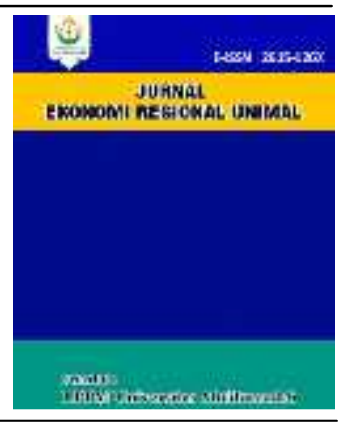

Aida Fitri ${ }^{* a}$,Khairil Anwar ${ }^{* b}$

*Fakultas Ekonomi dan Bisnis Universitas Malikussaleh

a Corresponding author: aidafitri731@gmail.com

bkhairil.anwar.semsi@gmail.com

\section{A R T I C L E I N F O R M A T I O NA B S T R A C T}

\section{Keywords:}

Village Fund, VillageFund

Allocation, Poverty.

\begin{abstract}
This study aims to determine how much Influence funds and village fund allocation have on poverty in Makmur District, Bireuen Regency. This study uses the panel data analysis method. Which is a combination of time-series data from 2015 to 2019, and a cross-section involving 27 villages and results in 135 observations. The results show that village funds have a negative and significant effect on poverty in the Makmur sub-district. Meanwhile, the allocation of village fund has no significant effect on poverty in the Makmur sub-district.
\end{abstract}

\section{PENDAHULUAN}

Masalah kemiskinan di Indonesia tidak dapat dipisahkan dari konteks kelembagaan dan tata kelola pemerintahan.Kemiskinan merupakan faktor mendasar sehingga menjadi inti dari pemasalahan yang di hadapi pemerintah.Mengetaskan kemiskinan menjadi tugas penting bagi pemerintah. Sehingga pemerintah telah banyak menyalurkan bantuan dalam bentuk apapun agar kemiskinan bisa teratasi.

Berikut adalah data kemiskinan desa, dana desa, alokasi dana gampong di Kecamatan Makmur Kabupaten Bireuen :

\section{Tabel 1}

Data kemiskinan desa, dana desa dan alokasi dana gampong di Kecamatan Makmur Kabupaten Bireuen 2015-2019

\begin{tabular}{|c|c|c|c|c|}
\hline \multirow{3}{*}{ Desa } & Tahun & $\begin{array}{c}\text { Kemiskinan } \\
\text { (Jiwa) }\end{array}$ & $\begin{array}{c}\text { Dana } \\
\text { Desa } \\
\text { (Rp) }\end{array}$ & $\begin{array}{c}\text { ADG } \\
\text { (Rp) }\end{array}$ \\
\hline \multirow{5}{*}{ Cotkruet } & 2015 & 312 & 268.172 .629 & 136.051 .080 \\
\cline { 2 - 5 } & 2016 & 298 & 590.534 .000 & 141.520 .787 \\
\cline { 2 - 5 } & 2017 & 287 & 752.256 .000 & 138.780 .000 \\
\cline { 2 - 5 } & 2018 & 256 & 696.326 .000 & 138.487 .000 \\
\cline { 2 - 5 } & 2019 & 235 & 751.174 .000 & 140.695 .000 \\
\hline
\end{tabular}

Sumber: Keuangan Kecamatan Makmur 2019

Pada Tabel 1 di atas menjelaskan bahwa setiap tahun kemiskinan di Kecamatan Makmurtelah mengalami penurunan angka kemiskinannya, dimana pada tahun 2015 sampai 2019 setelah adanya program dana desa maupun alokasi dana gampong telah banyak membantu masyarakat desa dalam membangun desanya menjadi lebih maju. Walaupun anggaran yang di salurkan tiap tahun terkadang lebih sedikit dari tahun sebelumnya juga mampu meringankan beban aparatur desa.

Dana desa terendah yang diterima selama 5 tahun telah berjalannya program ini diterima desa Cotkruet sebesar Rp268.172.629 sedangkan anggaran tertingginya diterima tahun ke 3 setelah adanya program ini sebesar Rp752.256.000. Sedangkan alokasi dana gampong terendahnya di terima pada tahun yang sama yaitu 2015 sebesar Rp136.051.080 dan tertinggi di terima pada tahun 2016 sebesar Rp141.520.787.

Penelitian ini bertujuan untuk mengetahui pengaruh dari dana desa,alokasi dana gampong terhadap kemiskinan di Kecamatan Makmur Kabupaten Bireuen.

Selanjutnya bagian kedua dari penelitian ini akan membahas tinjauan teoritis, metode penelitian akan dibahas pada bagian ketiga. Kemudian pada bagian ke empat akan dibahas hasil penelitian dan pembahasan. Pada bagian kelima akan membahas kesimpulan dan saran. 


\section{TINJAUAN TEORITIS}

\section{Kemiskinan}

Kemiskinan merupakan masalah multimensional yang penanganannya bukan hanya menyangkut faktor ekonomi semata tetapi juga meyangkut faktor sosial, politik, maupun budaya. Walaupun demikian masalah ekonomi tetap saja menjadi inti dari permasalahan kemiskinan(Ikhsan, 2010).

Kemiskinan adalah ketidakmampuan manusia dalam mencukupi keperluan dasar, seperti dalam hal kebutuhan yang kita butuhkan untuk bertahan hidup(Silalahi, 2014).

Masalah kemiskinan adalah persoalan mendasar dalam mengatasi permasalahan tersebut. Namun ada kalanya suatu kemiskinan itu terjadi akibat kondisi yang memaksa seseorang untuk miskin. Contohnya krisis ekonomi, gaya hidup Maupun budaya yang justru mengakibatkan masyarakat itu menjadi miskin. Hal tersebut juga dilandasi karena banyaknya keluarga yang terdata berada di sekitar garis kemiskinan (Prihartini, 2014).

\section{Dana desa}

PP No.60 Tahun 2014 menjelaskan tentang dana desa merupakan anggaran dari pemerintah pusat atau APBN yang di salurkan untuk desasebagai pelaksanaan dari ketentuan yang telah di tetapkan. Berdasarkan UU No.6 Tahun 2014 Desa di berikan wewenangan untuk mengurus dan mengelola anggran dari pemerintah tersebut sesuai dengan keperluan yang ditetapkan. Dana desa di gunakan untuk mendanai keseluruhan kebijakan desa sesuai dengan kebutuhan dan prioritas dana desa tersebut pemerintah menganggarkan dana desa secara nasional dalam APBN setiap tahunnya dengan mengefektifkan program yang berbasis desa secara merata dan berkeadilan (Juliana, 2017).

\section{Alokasi Dana Gampong}

Alokasi dana gampong adalah dana perimbangan yang diterima Kabupaten/Kota dalam anggaran pendapatan dan belanja Kabupaten/Kota setelah dikurangi dengan dana alokasi khusus. Pagu indikatif gampong merupakan patokan jumlah anggaran sementara yang di salurkan untuk masing-masing desa agar dapat merencanakan prosedur kerja maupun hal yang akan di laksanakan kedepannya dalam membangun desa agar lebih terampil dalam menjalankan program kerja sehingga mampu menjadi kan desa lebih unggul dari sebelumnya. Keuangan desa juga merupakan tanggung jawab dari semua pihak desa yang kemudian dapat di nilai dengan uang ataupun segala sesuatu yang berupa uang maupun barang yang berkaitan dengan anggaran yang telah di salurkan ke desa (Perbup, 2017).

Rozaki (2005) kebijakan ADD telah berjalan harus mempunyai tujuan besar dalam membangun kembali ortodoksi pemerintahan Kabupaten/Kota dalam menyerahkan kewenangan maupun pelayanan serta anggaran yang di salurkan untuk pemerintahan di level bawahnya yaitu desa harus dapat di pertanggungjawabkan oleh semua pihak yang berkaitan..

UU RI No 11 (2006)tentang pemerintahan Aceh (UUPA) menyebutkan gampong atau dengan sebutan lainnya adalah ketentuan masyarakat hukum yang berada di bawah kepimpinan mukim yang diberikan kewenangan untuk di pimpim oleh satu orang di desa atau sebutan lain yang berhak menberikan arahan maupun bimbingan kepada masyarakat desa. Adanya ADG yang memadai juga akan menunjang sumber penerimaan APBG, sehingga di harapkan mampu mendorong roda pemerintahan di tingkat desa, bahkan dalam menyelesaikan atau memenuhi kebutuhankebutuhan yang mampu di tangani di tingkat desa juga merupakan kewenangan Desa.

\section{Kerangka Konseptual}

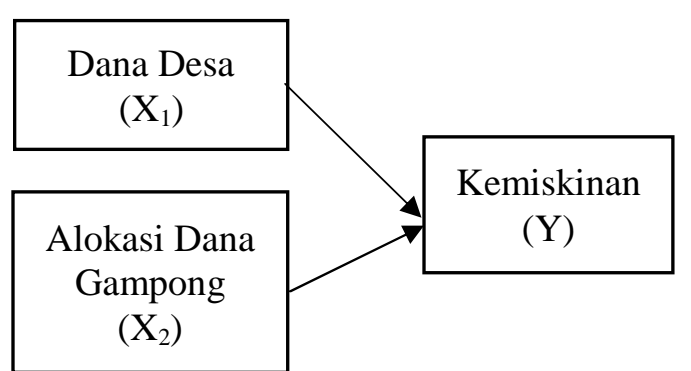

\section{Gambar 1. Kerangka Konseptual}

Kerangka konseptual gambar 1 di atas menjelaskan pengaruh antara variabel bebas terhadap variabel terikat, yaitu pengaruh (x1), 
dan(x2) terhadap kemiskinan (y) yang akan di uji secara parsial dengan menggunakan uji $t$, dan secara bersama-sama seluruh variabel independen terhadap dependen dengan menggunakan uji f.

\section{Hipotesis}

Adapun hipotesis alternatif yang diberikan dalam penelitian ini adalah sebagai berikut :

$$
\begin{gathered}
\mathrm{H}_{1} \text { : Dana desa berpengaruh signifikan } \\
\text { terhadap kemiskinan di Kecamatan } \\
\text { Makmur Kabupaten Bireuen. }
\end{gathered}
$$

$\mathrm{H}_{2}$ : Alokasi Dana Gampong berpengaruh signifikan terhadap kemiskinan di Kecamatan Makmur Kabupaten Bireuen.

\section{METODEPENELITIAN}

\section{Data dan Sumber Data}

Penelitian ini menggunakan data sekunder, data sekumder merupakan data yang telah diolah oleh pihak lain. Sumber data diperoleh dari kantor Kecamatan Makmur Kabupaten Bireuen. Data yang digunakan dalam penelitian ini dari tahun 2015-2019.

\section{Definisi Operasionalisasi Variabel}

Operasionalisasi variabel merupakan petunjuk bagaimana variabel-variabeldalam penelitian diukur. Untuk memperjelas dan mempermudah pemahaman terhadap variabel-variabel yang akan dianalisis dalam penelitian ini, maka butuh dirumuskan operasionalisasi variabel yaitu sebagai berikut:

1. Kemiskinan merupakan seseorang yang memilikipendapatan perkapita rata-rata perbulan di bawah garis kemiskinan, dengan satuan jiwa.

2. Dana desa merupakan anggaran dari (APBN) yang di peruntukkan untuk desa yang di transfer melalui (APBDK) dengan satuan Rupiah (Rp).

3. Alokasi dana gampong merupakan anggaran dari (APBDK). Satuannya Rupiah (Rp).

\section{Uji Asumsi Klasik}

Untuk mengetahui regresi tersebut cocok atau tidak di gunakan dalam penelitian. Apabila regresi tersebut cocok digunakan dalam penelitian harus mencukupi prosedur asumsi klasik dan terhindar dari masalah multikolineritas, heteroskedastisitas.

\section{Uji Multikolineritas}

Adalah untuk mendeteksi apakah terdapat hubungan yang signifikan antara beberapa maupun seluruh variabel bebas dalam pengujian. Untuk melihat terdapat multikolineritas berarti dapat dilihat dari nilai koefisien dari varibel independen harus lebih tinggi dari 0,80 berarti terjadinya multikolineritas (Gujarati, 2013).

\section{Uji Heteroskedastisitas}

Yaitu keadaan dimana varians dari setiap ganguan tidak konstan. Apabila hasil pengujian terhadap variabel bebas dengan nilai lebih dari 0,05 maka terbebas masalah heterokedastisitas (Gujarati, 2013).

\section{Metode Analisis Data Analisis Data Panel}

I. Common Effect Modeladalah model yang mengabaikan dimensi waktu dan ruang karena intercept dan koefisien slope di anggap konstan dan dalam melakukan regresi digunakan secara langsung regresi OLS.

II. Fixed Effect yaitu dalam melakukan model analisis ini memiliki asumsi adanya perbedaan intercept antar individu, tetapi intercept antar waktu sama dan koefisien regresi ataupun slope ama antar individu dan waktu.

III. Random Effect Model merupakan model yang memiliki asumsi bahwa slope antar individu nya sama, tetapi intercept berbeda baik antar individu maupun waktu sementara rata-rata tiap interceptnya adalah sama.

\section{Model Regresi Data Panel}

Model yang digunakan untuk mengetahui pengaruh dana desa, alokasi dana gampong, terhadap kemiskinan di kecamatan Makmur yang mengunakan analisis data panel merupakan kombinasi antar deret waktu dan deret hitung.

Model persamaannya adalah sebagai berikut:

$$
\text { Yit }=\beta_{0}+\beta 1 X 1 i t+\beta 2 X 2 i t+e
$$

Dimana: 
$\mathrm{Y}_{\mathrm{it}} \quad=$ variabel terikat untuk pengamatan ke $\mathrm{i}$ periode

$\beta_{1} \beta_{2}=$ koefisien regresi.

$\mathrm{X}=$ Variabel bebas

$\mathrm{e}=$ error

$\mathrm{i} \quad=$ Unit cross section (individual)

$\mathrm{t}=$ Periode waktu

Setelah memperhatikan satuan semua variabel penelitian, maka dalam hal ini peneliti mengunakan log pada regresi sehingga satuan yang digunakan akan menjadi sama, yaitu dalam satuan jiwa dengan persamaan sebagai berikut:

$\log Y=\beta_{0}+\beta_{1} \log \left(X_{1 i t}\right)+\beta_{2} \log \left(\mathbf{x}_{2 i t}\right)+e$

\section{Uji Spesifikasi Model}

1. Uji Spesifikasi Model Dengan Uji Chow

2. Uji spesifikasi model dengan uji hausman

3. Uji Spesifikasi Model Dengan Langrange Multiplier (LM).

\section{Pengujian Hipotesis}

\section{Uji Parsial}

Uji parsial yaitu untuk melihat seberapa jauh pengaruh variabel bebas secara tersendiri dalam menjelaskan variabel terikatnya. Apabila $t_{\text {hitung }}>t_{\text {tabel }}$ maka kita menerima hipotesisalternatif yang menjelaskan bahwa salah satu variabel bebas mempengaruhi variabel terikat(Ghozali, 2006).

\section{Uji Simultan}

menjelaskan apakah seluruh variabel bebas dalam satu model regresi mempengaruhi pengaruh secara bersamaan terhadap variabel terikat. Apabila $\mathrm{F}_{\text {hitung }}>\mathrm{f}_{\text {tabel }}$ maka $\mathrm{H} 1$ tidak diterima dan H2 diterima (Ghozali, 2006). Estimasi model pada software eviews 10, uji F dapat di lakukan dengan memperhatikan nilai $\mathrm{F}_{\text {hitung }}$ kemudian dibandingkan dengan nilai $\mathrm{F}_{\text {tabel. }}$

\section{Koefisien Determinasi $\left(\mathbf{R}^{\mathbf{2}}\right)$}

Koefisien determinasi yaitu untuk melihat seberapa besar pengaruh model dalam menjelaskan variasi variabel independen. Apabila ada penambahan satu variabel bebas yang di masukkan $\mathrm{R}^{2}$ akan meningkat itu tidak peduli apakah variabel bebas tersebut signifikan atau tidak.Dengan Demikian Nilai Adjusted $\mathrm{R}^{2}$ bisa
Digunakan Untuk Mengetahui Model regresi Yang Baik (Ghozali, 2006).

\section{HASIL PENELITIAN DAN PEMBAHASAN}

\section{Hasil Penelitian}

\section{Hasil Analisis Regresi Data Panel}

Hasil Uji Multikolinieritas

Uji multikolineritas di lakukan untuk melihat apakah terdapat hubungan yang linear yang signifikan antar variabel bebas. Untuk melihat terjadi atau tidaknya uji multikolinieritas maka di uji mengunakan correlationapabila nilai korelasinya di atas 0,80 maka terdeteksi terjadinya multikolineritas. Berikut adalah hasil pengujian multikolineritas.

\section{Tabel 2}

\begin{tabular}{|l|l|l|}
\hline & LOGX1 & LOGX2 \\
\hline LOGX1 & 1.000000 & 0.6130085 \\
\hline LOGX2 & 0.6130085 & 1.000000 \\
\hline
\end{tabular}

Sumber: Hasil Penelitian (Data Diolah, 2020)

Berdasarkan hasil pada tabel diatas antar variabel bebas adalahLOG(X1) dan variabel LOG(X2) berdasarkan hasil dari pengujian tidak adanya hubungan korelasi. Berarti penelitian ini terbebas dari pengujian multikolinieritas.

\section{Hasil Uji Heteroskedastisitas}

Untuk mendeteksi apakah dalam melakukan penguji terjadi heteroskedastisitas yaitu dengan memperhatikan nilai probabilitas Obs*R-squared. Apabila nilai probabilitas Obs*R-squared lebih tinggi dari tingkat alpha 5\% maka tidak adanya heteroskedastisitas.

\section{Tabel 3}

\begin{tabular}{|l|l|l|l|}
\hline \multicolumn{4}{|c|}{$\begin{array}{l}\text { Heterosk } \\
\text { edasticity }\end{array}$} \\
\hline F-Statistic & 0.940919 & Prob. F(2,132) & 0.3929 \\
\hline $\begin{array}{l}\text { Obs*R- } \\
\text { Squared }\end{array}$ & 1.897555 & $\begin{array}{l}\text { Prob. Chi- } \\
\text { Square(2) }\end{array}$ & 0.3872 \\
\hline $\begin{array}{l}\text { Scaled } \\
\text { Explained SS }\end{array}$ & 1.583060 & $\begin{array}{l}\text { Prob. } \\
\text { Squae(2) }\end{array}$ & 0.4532 \\
\hline
\end{tabular}

Sumber: hasil penelitian (data diolah, 2020)

Berdasarkan hasil pengujianmengunakan perhitungan dengan uji white test terlihat bahwa probabilitas dari Obs*R-Squared lebih tinggi dari alpha 5\% (0,3872>0,05). Dari hasil pengujian diatas berarti terbebas uji heteroskedastisitas.

Penentuan Teknik Estimasi Data Panel 


\section{Hasil Uji F Restricted (Uji Chow)}

Untuk mengetahui model manakah yang terbaik bisa memperhatikan nilai $F$ statistik dan nilai probabilitas $\mathrm{F}$.

\section{Tabel 4}

\begin{tabular}{|l|l|l|l|}
\hline \multicolumn{1}{|c|}{$\begin{array}{l}\text { Test Cross- } \\
\text { Section }\end{array}$} & \multicolumn{2}{l|}{$\begin{array}{l}\text { Fixed } \\
\text { Effects }\end{array}$} \\
\hline Effects test & Statistic & d.f. & Prob. \\
\hline Cross-section F & 12.532009 & $(26,106)$ & 0.0000 \\
\hline $\begin{array}{l}\text { Cross-Section } \\
\text { chi-square }\end{array}$ & 189.620744 & 26 & 0.0000 \\
\hline
\end{tabular}

Sumber: Hasil Penelitian (Data Diolah, 2020)

Berdasarkan tabel diatas nilai probabilitas $\mathrm{F}$ sebesar 0.0000 merupakan hasil dari Fixed Effect. Dari hasil menunjukkan nilai probabilitas $0,0000<0,05$, berarti menunjukkan bahwa model dalam penelitian ini yang terpilih yaitufixed effectmodel lebih cocok dari model common effect.

\section{Hasil Uji Hausman}

Dalam pengujian ini dengan memperhatikan nilai probabilitas chi-square. Apabila nilai pribabilitas chi-squarelebih tinggi dari nilai alpha 5\% maka model regresi data panel yang terpilih dalam penelitian ini adalah Random Effect. Berikut adalah hasil uji hausman.

\section{Tabel 5}

\begin{tabular}{|l|l|l|l|}
\hline & $\begin{array}{l}\text { Test cross- } \\
\text { section }\end{array}$ & $\begin{array}{l}\text { Random } \\
\text { effects }\end{array}$ & \\
\hline Test summary & Chi-Sq. Statistic & Chi-Sq. d.f. & Prob \\
\hline $\begin{array}{l}\text { Cross- section } \\
\text { random }\end{array}$ & 88.303540 & 2 & 0.0000 \\
\hline
\end{tabular}

Sumber: Hasil Penelitian (Data Diolah, 2020)

Menurut hasil dari penelitian memperoleh nilai probabilitas chi square sebesar $0,0000<0,05$. Maka model regresi yang terpilih dalam penelitian ini yaitu model FixedEffect.

\section{Analisis Data Panel}

Data panel yaitu kumpulan dari data time series dan cross section. Berdasarkan hasil yang di peroleh dari regresi yang digunakan dalam penelitian maka model terpilih model fixed effect. Hal ini dapat di ketahui dari hasil pengujian model regresi data panel.

Tabel 6

\begin{tabular}{|c|r|r|r|r|}
\hline Variable & Coefficient & Std. Error & t-Statistic & Prob. \\
\hline C & -18.60459 & 14.36289 & -1.295323 & 0.1980 \\
\hline LOG(X1?) & -0.314229 & 0.063412 & -4.955357 & 0.0000 \\
\hline LOG(X2?) & 1.606599 & 0.817011 & 1.966435 & 0.0519 \\
\hline
\end{tabular}

Sumber: hasil penelitian (data diolah, 2020)
Berdasarkan hasil tabel diatas maka dapat di peroleh persamaan hasil regresi sebagai berikut:

$Y=-18.604459-0.314229 X 1+1.606599 X 2$

Dari persamaan diatas menunjukkan bahwa nilai koefisien constanta sebesar -18.604459, artinya apabila variabel bebas dana desa dan ADG di anggap konstan, maka kemiskinan menurun sebesar $-18.604459 \%$. Nilai koefisien variabel $\mathrm{x} 1$ sebanyak0.314229, artinya apabila dana desa meningkat $1 \%$ maka kemiskinan akan menurun sebesar $0.314229 \%$. Selanjutnya adalah nilai koefisien dari variabel x2 sebesar 1.606599, artinya apabila variabel $\mathrm{x} 2$ meningkat $1 \%$ maka kemiskinan akan meningkat sebesar $1.606599 \%$.

\section{Hasil Uji Parsial}

Apabila nilai $t_{\text {hitung }}>\mathrm{t}_{\text {tabel }}$ maka variabel bebas tersebut berpengaruh terhadap variabel terikat. Berikut adalah hasil pengujian uji secara parsial.

\section{Tabel 7}

\begin{tabular}{|l|l|l|l|l|l|}
\hline $\begin{array}{l}\text { Variabel } \\
\text { Bebas }\end{array}$ & $\begin{array}{l}\text { t- } \\
\text { statistik }\end{array}$ & t Tabel & Prob & Keterangan & Hipotesis \\
\hline $\begin{array}{l}\text { Dana } \\
\text { Desa }\end{array}$ & 4.955 .357 & \multirow{2}{*}{1.97810} & 0.0000 & Signifikan & $\begin{array}{l}\text { Terima } \\
\text { H1 }\end{array}$ \\
\hline \multirow{2}{*}{ ADG } & 1.966 .435 & & 0.0519 & $\begin{array}{l}\text { T. } \\
\text { Signifikan }\end{array}$ & Tolak H2 \\
\hline
\end{tabular}

Sumber: Hasil Penelitian (Data Diolah, 2020)

Berdasarkan hasil pengujian variabel dana desa memiliki nilai $t_{\text {hitung }}=-4.955 .357>1.97810$, maka $H_{1}$ diterima, jadi variabel dana desa berpengaruh secara signifikan terhadap kemiskinan di kecamatan makmur namun secara negatif. Variabel Alokasi dana gampong memiliki nilai $t_{\text {hitung }}=1.966 .435$ $<t_{\text {tabel }} 1.97810$, maka $H_{2}$ ditolak yang artinya bahwa variabel alokasi dana gampong tidak berpengaruh secara signifikan terhadap kemiskinan di kecamatan Makmur.

\section{Hasil Uji F-Statistik}

Apabila nilai $\mathrm{F}_{\text {statistik }}>$ nilai $\mathrm{F}_{\text {tabel }}$ maka $\mathrm{H} 1$ diterima dan $\mathrm{H} 2$ ditolak, artinya secara bersamasama variabel independen memiliki pengaruh terhadap variabel terikat. Berikut hasil pengujian secara simultan.

Tabel 8

\begin{tabular}{|l|l|l|l|l|}
\hline $\begin{array}{l}\text { F } \\
\text { Statistik }\end{array}$ & $\begin{array}{l}\text { F } \\
\text { Tabel }\end{array}$ & Probabilitas & Keterangan & $\begin{array}{l}\text { Hipote } \\
\text { sis }\end{array}$ \\
\hline 27.60863 & 3.06 & 0.000000 & Signifikan & $\begin{array}{l}\text { Terima } \\
\mathrm{H}_{1}\end{array}$ \\
\hline
\end{tabular}

Sumber: hasil penelitian (data diolah, 2020)

kan hasil pengujian memperoleh nilai dari $\mathrm{F}_{\text {hitung }}=$ 27.60863, sementara nilai dari $\mathrm{F}_{\text {tabel }}$ di peroleh 
sebesar 3.06 dari alpha 0,05. Sehingga bisa kita lihat nilai $F_{\text {hitung }} 27.60863>F_{\text {tabel }} 3.06$, maka secara bersama-sama dengan tingkat kepercayaan 95\% variabel bebas yaitu dana desa,alokasi dana gampong berpengaruh terhadap variabel terikat yaitu kemiskinan di Kecamatan Makmur.

\section{Koefisien Determinasi $\mathbf{R}^{\mathbf{2}}$}

Hasil nilai dari Adjusted R- Square dalam pengujian yaitu sebesar 0,847561 hasil tersebut menjelaskan hubungan antara variabel bebas dengan variabel dependen dalam pengujian adalah kuat sebesar $85 \%$ sedangkan $15 \%$ lainnya di pengaruhi oleh variabel di luar penelitian ini.

\section{Pembahasan}

\section{Pengaruh Dana Desa Tehada Kemiskinan Di Kecamatan Makmur}

Berdasarkan hasil pengujian bahwa variabel dana desa berpengaruh secara signifikan terhadap kemiskinan desa di Kecamatan Makmur pada tahun 2015-2019. Penelitian ini sesuai dengan teori yang di sampaikan (Susilowati et al., 2017)dana desa dapat mempengaruhi kemiskinan desa, sehinnga angka kemiskinan akan berkurang. Dengan semakin besarnya anggaran dana desa di harapkan semua keperluan yang dibutuhkan oleh desa dapat terpenuhi. Kemampuan maupuan potensi sekitar juga mampu dikembangkan, serta SDA dan lingkungan dapat di manfaatkan secara berkelanjutan yang kemudiannya juga akan menunjang kemajuan maupun pendapatan masyarakat desa semakin meningkat.

Hasil penelitian ini juga sama dengan yang dilakukanSari, 2017) di Kabupaten Tulungagung. Dana desa berpengaruh secara negatif namun signifikan terhadap kemiskinan di Kabupaten Tulungagung.

\section{Pengaruh Alokasi Dana Gampong Terhadap Kemiskinan Di Kecamatan Makmur}

Berdasarkan hasil pengujian secara parsial pada variabel alokasi dana gampong dalam pengujian ini tidak memiliki pengaruh yang signifikan. Tabel 10 menjelaskanbahwa probabilitas dari variabel alokasi dana gampong sebesar 0.0519, sehingga diperoleh hasil alokasi dana gampong di Kecamatan Makmur tidak memiliki pengaruh yang signifikan terhadap kemiskinan.

Hasil pengujian searah dengan penelitian yang dilakukan oleh (Lalira et al., 2018) yang hasilnya alokasi dana gampong tidak memiliki pengaruh yang signifikan terhadap penurunan kemiskinan di Kecamatan Gemeh Kabupaten Talaud.

\section{KESIMPULAN DAN SARAN}

\section{Kesimpulan}

Dari hasil pengujian dapat di peroleh kesimpulan antara lain:

1. Variabel dana desa berpengaruh secara negative dan signifikan terhadap kemiskinan di Kecamatan Makmur.

2. Variabel alokasi dana gampong tidak berpengaruh secara signifikan terhadap kemiskinan di Kecamatan Makmur.

\section{Saran}

Dari hasil penelitian yang telah di lakukan maka penulis memberikan beberapa saran yaitu:

I. Saran bagi mahasiswa semester akhir untuk lebih tertarik meneliti permasalahanpermasalahan di sekitar kita. Sehingga dapat memberikan berbagai macam solusi dalam menyelesaikan masalah yang di teliti.

II. Saran bagi pemerintah Kecamatan Makmur agar lebih memberdayakan sumberdaya alam dengan seefektif mungkin serta mengenali dan mengali potensi yang di miliki oleh masing-masing desa, sehingga desa tersebut mampu menyelesaikan permasalahan-permasalahan yang di hadapi oleh desanya sendiri serta mampu mengali sumberdaya sesuai dengan kemampuan yang dimiliki.

III. Bagi peneliti menyarankan kepada peneliti selanjutnya untuk melakukan penelitian yang sama. Namun menambah beberapa variabel lainnya.

\section{DAFTAR PUSTAKA}

Ghozali, I. (2006). Aplikasi Analisis Multivarite dengan SPSS, Cetakan Keempat. Badan Penerbit Universitas Diponegoro: Semarang. 
Gujarati. (2013). Dasar-dasar Ekonomitrika. Salemba Empat: Jakarta.

Ikhsan, M. (2010). Pidato pada Upacara Pengukuhan sebagai. November.

Juliana, E. (2017). Efektivitas Dana Desa Dalam Menunjang pembangunan Perdesaan Di kabupaten Asahaan. Jurnal Fakultas Ekonomi dan Bisnis.

Lalira, D., Nakoko, A. T., \& Rorong, I. P. F. (2018). Pengaruh Dana Desa Dan Alokasi Dana Desa Terhadap Tingkat Kemiskinan Di Kecamatan Gemeh Kabupaten Kepulauan Talaud. Jurnal Berkala Ilmiah Efisiensi, 18(4), 62-72.

Perbup. (2017). Tata Cara Pembagian dan Penetapan Rincian Pagu Indikatif Alokasi Dana Gampong.

Prihartini Budi Astuti. (2014). Efektifitas dan Pengaruh PNPM Mandiri Perdesaan, Alokasi Dana Desa, Pendapatan Asli Daerah dan Jumlah Penduduk terhadap Kepala Keluarga Miskin di Kabupaten Kebumen 2009-2011. Eko Regional FEB UNSOUED, 9(2), 89-101.

Rozaki, A. (2005). Prakarsa Desentralisasi Dan Otonomi Desa. In Yogyakarta: Ire. Press.

Sari. (2017). Analisis Ekonomi Kebijakan Dana Desa Terhadap Kemiskinan Desa di kabupaten Tulungagung. Jurnal Ekonomi Pembangunan, 15(1), 34-49.

Silalahi, R. (2014). Pengantar Ekonomi Makro. In Bandung: Citra Pustaka.

Susilowati, N. I., Susilowati, D., \& Hadi, S. (2017). Pengaruh Alokasi Dana Desa, Dana Desa, Belanja Modal, dan Produk Domestik Regional Bruto Terhadap Kemiskinan Kabupaten/Kota di Jawa Timur. Ilmu Ekonomi, 1(4), 514-526.

UU RI No 11. (2006). Pemerintahan Aceh. 